\title{
The Intact Public Health Care System in Cuba: An Exploration of its Motivations and Transferability
}

\author{
So Youn Kim
}

Cuba has the highest average life expectancy and lowest ratios of physicians to patients per capita, as well as the lowest infant and child mortality rates among 33 Latin American and Caribbean countries. This paper will answer the research questions, "what lessons can be learned from the Cuban health care system", and "can its success be attributed to its unique economic and social context, or can it be transferred to other countries?" With the strong commitment to public health care and faced with limited resources and economic isolation, Cuba has maximized its capability with systemic efficiency and the education of its given population. This paper will begin with an overview of Cuba's Political, Social and Economic Context. Then, it will discuss key emerging themes and assessments of Cuban Health Care System; financing, medical products, human resources, health service delivery and health information system. This paper will then provide policy responses and outcomes and offer analysis and policy implications. Then, policy recommendations will be provided. Lastly, the paper will discuss the prospect of Cuba's health care system given the situation that the US has recently lifted its embargo on Cuba that Cuba is not in economic isolation anymore with the recognition of Cuba's increasing geopolitical influence in the world through medical services.

Key Words: Public health care, Cuban health care, Primary health care

O f 33 Latin American and Caribbean countries, Cuba has the highest average life expectancy of 78.6 years and lowest ratios of physicians to patients per capita (59 per 10,000), as well as the lowest infant

*So Youn Kim (so.youn.kim@uwaterloo.ca) received her Bachelor of Arts (Honors) in International Relations with distinctions from Western University and received Master of Arts degree at the Norman Paterson School of International Affairs at Carleton University in Ottawa. She is now a PhD student of Global Governance program at Balsillie School of International Affairs at University of Waterloo in Canada. Her various research interests include global environmental politics, Southeast Asian studies, and Cuban history and culture. So Youn wishes to thank Prof. Valerie Percival for her guidance. 
(5.0/1000 live births) and child (7.0/1000 live births) mortality rates (Drain and Barry 2010, 572). This paper will answer the research questions, "what lessons can be learned from the Cuban health care system," and "can its success be attributed to its unique economic and social context, or can it be transferred to other countries?" With the strong commitment to public health care and faced with limited resources and economic isolation, Cuba has maximized its capability with systemic efficiency and the education of its given population. Isolation has in fact made Cuba's health care more intact and stronger. This was the ideologically driven goal of the state's duty to public health. This improvement will, in turn, prove the legitimacy of the socialist government to continue its power. Thus, it was an unavoidable decision for the government to support public health; an attempt to silence internal complaints about disconnection from the world.

\section{THEORETICAL FRAMEWORK}

This paper will be grounded on a theory of governmentality from Foucault. According to Herzog et al, governmentality is defined as "an active recognition of the effects of governmental action" on its subjects (Herzog et al 2016, 37). Foucauldian tradition is viewing governing exercise as part of production of docile and disciplined bodies under disciplinary institutions. This can be likened to how Cuban government aims to control its population under the health care system of the particular kind - preventive care system with comparatively economical cost and infrastructure (Kotkas 2010, 175). Such control over bodies of the people show negative side of modern institutions - infringement of privacy under panopticon control from one centralized body of the government. Despite Foucault's notion of judicial liberties and presumption of democratic government with the parliamentary mechanisms and "judicial egalitarianism," the Cuban government of socialist origin is comparable because of the systemic nature of Cuban health care system. The mix of centralization and decentralization of Cuban government's health care system cuts cross democratic tradition of the government toward non-western types of governmentalities, which is deeply related to its political, cultural and historical contexts. While the autonomy of the population is not into consideration in this paper, the very act of biopolitical control by state government over its subjects is a deliberate attempt, which involves surveillance activities of consistent watching over its subjects. The purpose of government to create "utopian" and docile population (Herzog $2016,48)$ discloses the very objective of cost-effective medical care: maintaining 
of the government's legitimacy and protection of its economic and political system in face of the isolation. This distinct condition makes what Cuban health care system unique: that difficulty to be in successful compared to other open economies thus gives us lessons for future direction of our health care system, showing that health care system does not have to be expensive and rampant with private controls. Furthermore, accumulation of data about its population for socalled health purpose is another form of biopolitics over its subjects. Despite outdated infrastructure, collected idea is very act of government surveillance over its nonphysical forms of information - this is embedded into privacy control by the Cuban government.

\section{OVERVIEW OF CUBA'S POLITICAL, SOCIAL AND ECONOMIC CONTEXT}

The most influential event in Cuban history was the revolution led by Fidel Castro in the 1960s. After the revolution, the socialist regime paid the issue of public health much more attention. In the 1976 Constitution as well as the 1983 Public Health Law, health was recognized as a basic right to each citizen and it was the duty of a state to provide health care (Keck and Reed 2012, 13; Magnussen et al 2004, 79; Pagliccia, and Pérez 2012, 79). People are viewed as the labor force and main economic driver of the country. Thus, the government nationalized private clinics and pharmaceutical companies (Keck and Reed 2012, 13; De Vos 2005, 192). With economic assistance from the USSR that continued until the 1980 s, Cuba increased the physician-to-population ratio as well as invested in research and development; two percent of national health expenditure and five percent of externally funded programs were given to research (Spiegel and Yassi 2004, 97). As such, the regime also focused on preventive care and the availability of free medication for people.

With the collapse of the USSR as well as the US embargo in the 1990s, Cuba's situation shifted into economic and political isolation. The US Torricelli bill in 1992 and Helms-Burton Act in 1996 resulted in decreased trade between Cuba and the US, and other countries. Almost 90 percent of Cuba's trade with the US was food and medicines (Spiegel and Yassi 2004, 96). As a result, in the late 1990s, only a few international pharmaceutical companies supplied essential medicines to Cuba and in 1996, with Cuban national formulary of 1300 medical products reduced to 900 (Drain and Barry 2010, 571).

The result was the deterioration of health services and infrastructures and an increase in the risk of diseases, such as dengue, due to lack of medication. A 
nutrition problem also developed. Caloric intake decreased by 40 percent and the number of underweight newborns increased by approximately 23 percent. Anemia occurred among pregnant women, and the number of surgeries carried out decreased by 30 percent. The total mortality rate increased by 13 percent. The national epidemic of optic-related diseases increased in 1991 due to malnutrition (Drain and Barry 2010, 571).

While Cuba was excluded from the neoliberal free trade agreement boom under the influence of the World Bank and IMF in Latin America (Spiegel and Yassi 2004, 90), it faced a situation that would change its future. Eventually, Cuba chose to focus on preventative care for economic and ideological reasons: early diagnosis, vaccination, and primary care could reduce the substantial cost that would be spent on treatment of diseases (Starfield et al 2005, 474). In this way, a healthier Cuban population could maintain its economy while isolated by the common market. This achievement, in turn, would improve the legitimacy of the regime to continue its socialist rule.

\section{KEY EMERGING THEMES AND ASSESSMENTS OF CUBAN HEALTH CARE SYSTEM}

\section{FINANCING}

Despite the lack of medical supplies as well as the economic isolation, Cuba tried to maintain its health budget. In 1990, Cuba had suffered economically from the decline of socialism in Eastern Europe and the collapse of the USSR. Foreign trade was reduced by 90 percent in just a few years (De Vos 2005, 196). However, Cuba continued its course. For example, the budget allocated for national research programs and development of biotechnology increased and those institutions responsible were ordered to further focus their research (Magnussen et al 2004, 170). However, health care and other sectors had initially experienced a 50-percent reduction in their budgets (De Vos 2005, 196). Despite the state of the economic situation, the government maintained its universal health care system.

In 2014, one of Cuba's official media outlets reported that the government would earn $\$ 8.2$ billion from its medical workers outside of the country. Cuba's medical internationalism has helped Cuba gain hard currency and broadens its geopolitical influence with other countries such as Venezuela. Thus, Cuba has managed to maintain its health care system despite financing issues from the US embargo and consequent economic isolation. Finance is considered important because it contributes to the efficiency of its health care system and 
economy of the country. This source of currency could allow Cuba to manage its public systems, including the health sector, and sustain its economy despite disconnection from the Western world. New paragraph: use this style when you need to begin a new paragraph.

\section{LEADERSHIP/GOVERNANCE}

The government, within its ideological framework, has been committed to protecting health as a human right. Since the early revolution's application of the Alma Ata Declaration, which decreed that health is an intrinsic right, Cuba has continued its principle of "health for all" (Spiegel and Yassi 2004, 97; Pagliccia and Pérez 2012, 78) With universality, equitable access and government control (Keck and Reed 2012,13), and despite the presence of economic suffering and resultant deterioration of medical equipment and facilities (De Vos 2005, 202). Such national context and isolation from outside have motivated Cuba to be stronger and more intact. This allows the country to continue its socialist rule with legitimacy.

Cuba utilized centralization to increase the efficiency of its health system. The health care system is centralized and governed under the leadership of the Ministry of Health Care, which was established in 1976 to boost the knowledge, competencies, and responsibilities of health science professionals. Its responsibilities are also decentralized up to regional and district levels (De Vos 2005; Keck and Reed 2012). This shows how the government was able to control diseases and their risk factors, and helped to set local priorities for disease prevention, diagnosis, treatment and rehabilitation with some local flexibility (Keck and Reed 2012, 113).

\section{MEDICAL PRODUCTS}

A lack of medical supplies is the core problem of Cuba's health system. Cuba's capacity to produce high quality innovative medical products was significant and worked somewhat effectively before the imposed embargo. For example, the invention of interferon for cancer and other viral infections deserved considerable praise since at the time only eight industrial countries could produce it (De Vos 2005, 195). After the embargo, however, importation of medical supplies was reduced to one-third of that in 1989. With the difficulty of importing raw materials, local production of pharmaceutical products stopped. Suspended contracts for medical supplies with US subsidiary companies was another situation Cuba faced (De Vos 2005, 197). The scarce medical supplies are still one of the fundamental problems that Cuba has. 


\section{HUMAN RESOURCES}

After the US embargo, the population of Cuba was considerably sick. Cuba needed a healthy population to drive its economy internally while externally it was disconnected from the world. At the same time, Cuba needed medical workforces to treat this population. This, in turn, would gain popular support for the government. By giving care, the government reduced the frequency of complaints. With the good name as doctors, those workforces might be used to carefully watch its population and remove the possibility of deviation.

Cuba recognized the absence of doctors who left the country after the revolution - more than 3000 of the 6000 physicians had emigrated. Thus, it carried out extensive and inexpensive medical education policies under Rural Medical Service in 1960 (Keck, and Gail 2012, 13). The Cuban government has provided financial incentives to increase the amount of medical personnel by offering free education and the requirement of academic grades as the sole criteria for admission (Keck, and Gail 2012, 14). The curriculum included clinical skill learning and public health services so that doctors and nurses could care for the general health of people as well as treat disease and injury (Keck, and Gail 2012,15). The is a strong emphasis on service learning in community accords with Cuban government's health policies. Thus, the health workforce, including community health workers, was educated to address social, cultural and economic factors of health with a focus on preventative health care Keck, and Gail 2012, 14). With the publicly educated health workforce, the government could provide guidelines and direction in community health care. As a result of close care from family doctors, the healthier population would contribute to the economic situation of Cuba and continue the rule of the socialist party.

\section{HEALTH SERVICE DELIVERY}

Cuba's distribution of health service delivery has improved since the revolution. The government has educated more doctors and encouraged them to practice in remote rural areas. With the inclusion of clinical skill and service learning, at the end of residency, 65 percent of physicians start primary care medicine. The rest typically move on to special training (Drain and Barry 2010, 573).

The core component of the Cuban health care system is its focus on preventive care and utilization of decentralization and centralization. The structure of the health care system is organized effectively as each specific level of duty is allocated to each according to the level of care that patients require. The first line of health care is comprised of community-based polyclinics and family medicine, referred to as consultorio (Drain and Barry 2010, 573). Every family doctor or general practitioner has a duty of first line health care of prevention, health 
education, curative care, and rehabilitation for 500-800 people (De Vos 2005, 194).

Family doctors and patients live in the same community and maintain close relationships. This enables medical consultation at clinics as well as in-home visits within the community, which provide effective health service delivery regarding proximity and closeness (De Vos 2005, 194). The second line is comprised of municipal hospitals, and tertiary care is comprised of special hospitals at a provincial level. Finally, fourteen institutions are working on research as well as clinical care in a specified field. These comprise an organized and well-distributed health care system, which allows for wider health coverage, technical capacity, and ultimately more efficient health care delivery. This coordination of medical care with health promotions is based on data and an evidence-gathering system. This efficiency in the health care delivery system allows the government to watch the people in each community closely. Family doctor function as representatives of the regimes to treat people in exchange for information including medical record and history.

\section{HEALTH INFORMATION SYSTEM}

As mentioned in the previous section, the monitoring system of Cuba essentially monitors people's lives and medical histories. The Cuban monitoring system, under the National Statistics Division, has been effectively carried out into every sphere of human life. This way, Cuban government guaranteed effective prevention of epidemics and detection of early diagnosis minimized cost and sufferings.

There are continuous assessment and risk evaluation of any potential impacts on individual health. Through the accumulation of medical history, physical examinations, analysis of home environments, and the analysis of features of neighbour hoods, the government can detect disease patterns, predict disease behaviours and set up intervention strategies. As such, people are categorized by risk factors such as smoking habits, weight, diabetes risk, or hypertension for the institute to decide whether it should intervene (Starfield et al 2005, 463). When patients require consultation for specific a case, they are directed to the hospital (Keck, and Reed 2012, 114). Such collection of records functions as effective means of managing its health care system and at the same time allows the government to control its population at an intrusive level. 


\section{POLICY RESPONSE AND OUTCOMES}

The US embargo and subsequent economic isolation resulted in a deterioration of the quality of health services. While most of the budget had been reduced, the government continued to strive for universal health care strategies since it is crucial for its continued rule. In 1997, the Cuban economy has grown again and the government under the Cuban Communist Party (PCC) could strengthen its credibility given its strong links with the population and huge participation of workers (De Vos 2005, 198). The health care system has been free, preventive, curative, and has provided rehabilitation services. This would allow for the improvement of the general health of majority of the population.

The socialist ideology was backbone of the driving factor of Cuba's health care policy. For example, Cuban child from its birth has equipped with socialist ideology and those become doctors have particular ethics on their medical practice. Cuban physicians work longer hours compared to financial compensation they receive. In 2002, while government work was paid around 100 pesos (\$4), a college professor was paid 300-560 pesos (\$12-22), doctors were paid 350-60o pesos (\$12-25) despite its long hours of work. One Cuban dentist recognized his situation: "It is a very stressful job, low pay, long hours, and I don't feel very appreciated" (De Vos 2005, 196). The teaching philosophy of the National School of Public Health instead claimed that "socialist ethics is inculcated in every child in Cuba" since youth, that the principle is that professionals work where they are demanded most. Thus, since the beginning of one's dream to be a doctor, Cuban person has this strong ethics of socialist and patriotism toward government, situating himself at the work scene of where they most need one (De Vos 2005, 196). Such ideologically driven education by Cuban government is also the very core of its health care system in overall picture. The sustainment of its government with patriotic desire for their contribution to the society is in every heart of Cuban people from their beginning of lives as a working professional in every sector of the society. This ideology was still alive in Cuban society because despite difficulty of the job, Cuba did not experience substantial decrease in health worker in the early 1990s, when booming tourism industry might have attracted more people into its industry (De Vos 2005, 197). Where health workers receive slight compensation, the government mobilized moral incentives and created pride with ceremonies and in speeches, continuously imbuing health workers with energy to go for development and innovation in health care field (De Vos 2005, 198).

Furthermore, as an example, a national screening system called the HIV Public Health Program was carried out. With products from investment in 
biotechnology and genetic engineering, Cuba could produce new vaccines and medications and develop advanced diagnostic procedures. Cuba could produce three proteins of HIV virus, which are utilized in the diagnosis of AIDS. Ultimately, Cuba could control an HIV/AIDS epidemic, with reports of HIV prevalence of $0.03 \%, 1 / 11$ of the US (De Vos 2005, 195).

A preventative care system entailed a strong vaccination program for illnesses including polio and diphtheria, and in turn prevents spread of the disease and save on individual treatment (De Vos 2005, 196; Starfield et al 2005, 465), Mass organizations such as Committees for the Defense of the Revolution and Cuban Women's Federation participated in polio vaccination campaign in 1962 (De Vos 2005, 193). By the most serious period of the early 1990s, Cuba carried out 35 domestic polio campaign and offered approximately 64 million doses to its people. By the 2000s, Cuba successfully vaccinated $90 \%$ of children and adults among its population (De Vos 2005, 193). According to data, Cuba had almost zero in number of occurring patients only a year after. In contrast, other South American countries had experienced severe polio patients in the 1970s. In such way, Cuba eliminated diphtheria in 1980 and measles in 1993 (Cooper et al 2006, 821). These routine vaccinations resulted in 98.5 percent vaccination rates among children below the age of two (De Vos 2005, 196). Preventionfocused health care entails categorizing and providing close care to patients and fumigation and clean-up campaigns in response to epidemics - Cuba has effectively prevented Dengue and possibly Zika (Grandin 2016) this way. Less expensive vaccination prevents the development of diseases that would require substantial costs to cure or treat, and therefore result in a sicker population. Thus, this vaccination campaign is effective and proven worthy in the costbenefit calculation. A healthy population with reduced costs can contribute positively to the economy of the country.

As an example of public health policy for comprehensive care, the 1983 Family Doctor and Nurse Plan, made doctors and nurses part of the community of being able to respond to emergencies quickly (Spiegel and Yassi 2004, 98). With its medical education policies, Cuba had one physician for every 175 people in 1999 (Spiegel and Yassi 2004, 98). Currently, Cuba has 90,00o doctors for a population of 11 million, translating to eight doctors for every 1000 citizens (Hill 2016). Centralized government control can provide a full-coverage system that links consultorios, polyclinics, and municipal, provincial, and specialized national hospitals (Spiegel and Yassi 2004, 98). When necessary, patients were directed to higher levels of care. These horizontal and vertical elements of the system functioned to effectively manage its population. These services would silence complaints because all patients were deemed to be treated equally. 
Furthermore, there were efforts to replace hospital service with polyclinic care: in 1970 , the ratio between polyclinic and hospital service was $69.6 \%$ to $24.6 \%$ but in 2000 , it was deepened as to $84.5 \%$ to $14.7 \%$. In 2009, it became $88.9 \%$ to 10.4\% (Thomas 2016, 194). In addition, Family Doctor Program was launched to increase number of doctors and nurses every corner of the house. According to data, the program reduced hospitalization and number of patients who use emergency room, enhanced watching and well-being of patients by campaigning on healthy life habit. As a result, increase in number of health workers witnessed decrease in morality. For example, increase of $1 \%$ in the number of health care workers reduced infant mortality of 0.17 every 1000 live births. There has been evident decrease in child mortality in the 1990s, showing evidence that Cuban health care system worked well according to the direction of government policy (Thomas 2016, 195).

Cuba had experienced the extensive diminishing of infant morality between 1970 and 1985 , from 38.7 per 1000 live births to 16.5 per 1000 live births, creating 57\% decrease. Up to Special Period when Cuba carried out Family Doctor Program, the rate consistently was reduced from 16.5 per 1000 live months in 1985 to 7.2 per 1000 live births in 2000, producing $56 \%$ decreased. The rate continued to decrease to 4.8 per 1000 live births in 2009, which is $33 \%$ decrease (Thomas 2016, 193).

Furthermore, in such community-oriented care, social and non-medical determinants of health (NMDH) were addressed. This helped to create a healthier environment (Thomas 2016, 99). High investments were carried out in human capital through the provision of health care, education, and housing is carried out (Thomas 2016, 101). This is done through wide mobilization, volunteering labor, cooperation, promotion, which addressed collective necessity (Thomas 2016, 101). This is a broader sense of ideological campaign that manages lifestyle of the population.

As a result, Cuba's health data is similar to that of developed countries. The main cause of death is non-communicable diseases such as heart disease and cancer over infectious and parasitic diseases. It can be said that "Cuba lives like the poor and dies like the rich" (Thomas 2016, 88). Cuba has lost economic benefits that could have incurred from connecting with the Western world. However, it has gained generally healthy population who live longer. A strong workforce would enable Cuba to continue its governmental system despite economic isolation. This isolation may eventually strengthen its commitment and health care system intact. 


\section{ANALYSIS AND POLICY IMPLICATION}

Throughout the assessment of Cuba's health care system, there are some pitfalls worth mentioning. This accords with socialist government's dogmatic obsession with collecting everyone's records and reaching out to other countries that could benefit Cuba. Essentially, the reason is that Cuba can strengthen the legitimacy of its socialist regime.

First, the reported statistics might not represent the whole and actual local conditions. In such a totalitarian state where the government controls education, society, and media, its announcement on statistics might not represent their true conditions (Nordlinger 2016). The government, aware of about the perception of the world, would be likely to care about indicators that would represent the general health of a country. For this reason, doctors are guided to focus on prenatal and infant care to reduce infant mortality rate.

Second, the health care system in Cuba is intrusive. Women's pregnancy is closely monitored with care, but those with risks face cruel and difficult decisions. At-risk pregnant women receive home visits by their doctor every seven to 15 days. If necessary, genetic testing is carried out within 15 weeks of registering a pregnancy. An additional obstetrician is introduced at 26-34 weeks in addition to family doctor clinic (Frist 2016). At any sign of abnormality, it is recommended that the pregnancy is terminated (Nordlinger 2016). This explains the surprisingly low infant mortality rate of 4.2 deaths per 1000 births (Frist 2016). The Cuban health care system is also intrusive in that there is no privacy. For example, one doctor in Cuba, Dr. Pina, knows each of the 400 individuals in her community (Frist 2016). Closeness between family doctors and their patients and all the medical histories they record might be intrusive. Such a national check-up system and disclosure of personal disease prevent privacy. Some patients are afraid of exposing their medical conditions or diseases due to social discrimination. In this way, family doctors might be a means for the government to carry out intrusive health care that surveys the lives of its citizens.

Third, the system is ideologically driven so that any small deviation from its guidelines is considered unacceptable. Any private clinic is absolutely prohibited from providing care for underprivileged or desperate patients (Nordlinger 2016). The totalitarian regime warned in one report that "new dissidents in the public health sector will not be tolerated" (Nordlinger 2016). This prohibitional warning shuts off advantages of private system to take place. Cuba can adopt a type of competitive system between different medical products, for example, to improve its quality. Thus, there is no scope for private care or private-public partnership for better health service in Cuba. 
Fourth, along with its ideology, particular countries were well visited than others as Cuba's focus on socialist regimes - Chavez's Venezuela, Morale's Bolivia and Mugabe's Zimbabwe (Nordlinger 2016). It would be beneficial to question why Cuba supports medical services to these dictatorial governments who were found to abuse human rights on a greater scale. Cuba, for political reasons, places the faults of limited resources solely on US embargos. This is part of propaganda mindset that had been dominant in society under Cuban government. This shows that Cuba's health policies, especially global, are partially driven by ideology and socialist bloc philosophy, not as genuine humanitarian efforts to save people from diseases and reduce the number of deaths.

Fifth, the recorded history is handwritten, and equipment is "outdated." Examples within Dr. Pina's clinic are a heavy metal desk, molded plastic chair, and handwritten check marks on the map (Frist 2016). In her clinic, there are "no electric medical records, no patient management system, no computer" (Frist 2016). This old equipment and data system shows the weakness of Cuba's medical system, questioning if there is enough money to carry out necessary and essential medial services. This primitive form of Cuba's health system is due to limited resources and equipment. Similarly, Cuba's most important weakness is its lack of medical supplies and products (Feinsilver 2016). This results in the presence of a black market and, accordingly, the overpriced products will not be available to every Cubans (De Vos et al 2009, 1576). Several pieces of medical equipment might be outdated due to lack of budget for replacements. If certain equipment needs to be fixed or replaced but cannot be, the community dependent on this clinic will face problems.

Sixth, some claimed that the Cuban government focuses on the exportation of doctors abroad instead of its nationals; this claim demonstrates government medical facilities and pharmacies' disproportionate attention to internationals in search for hard currency. There are "two tiers of an economy": US currency and Peso currency, and certain products can only be bought in US currency despite complaints from Cubans who need and want to buy them in Peso currency (Brotherton 2012, 164). If Cuba cannot solve its scarcity of medical supplies and lack of foreign currency in the economy, these will remain problems. These minor frictions between Cuban citizens are the ones that the Cuban government has omitted to control or neglected to control given the substantial amount of population who show such behaviours.

Seventh, prospect for preventative care systems should be examined. For example, there exists a question of how Cuba will deal with its aging population, which experiences chronic conditions. They would need rehabilitation and 
substantial costs for treatment (Keck and Reed 2012, 17). How Cuba will effectively deal with this new trend of increasing number of people with the noncommunicable disease is important because there will be substantive medical costs for those population for management and cure. This would be seen as a future burden for Cuba, which pursues economic efficiency; thus, this problem should be addressed.

\section{POLICY RECOMMENDATIONS}

There are two questions to be addressed: Is Cuba's health care system transferrable, and what are the lessons to learn? Most recommendations are applicable if there is enough of a budget and capacity to put into, for example, annual check-ups for every individual people or subsidize medical school tuitions. The municipal and provincial government should need to consider the availability of community workers to make community - oriented health environment. The key point to make is that the health care system should exist under in the public sector rather than private. This move away from private toward public must be geared as a backbone of these recommendations. While Cuba's health care system is ideologically driven and potentially intrusive, and other countries in situations of isolation might follow in Cuba's footsteps. However, many countries exist freely with large flows of materials and information, and this can be seen as being in a somewhat better position than Cuba.

This section provides recommendations based on Cuba's health care system. Despite difference in health care structure compared to Cuba, the recommendations outlined does not require drastic changes. For example, strong government leadership and equity-based policies are similar to many welfare-related policies that can be carried out by the governments in different countries. If governments do not overlook those underprivileged segments of population into societal concerns, this is in similar line to what is proposed in this paper. One, moving away private health care toward public health care needs significant restructuring for countries like the US where privatization of health care is prevalent. However, Obama care which was tried into the US health law in several years ago showed that preventive and affordable care through insurance is possible. The Obama Care included people who could not be insured previously thus could not afford treatment, placing themselves in the emergency room with highly progressed diseases. The Obama Care enabled these people to receive health care and made health cost affordable (Amadeo 
2019). The very fact that Cuban health care was economical, prevention-focused and without need for sophisticated medical technology makes what this type of health care system applicable and transferrable to other countries. At least, an awareness for simple but intact health care system is thought-provoking, changing what we perceive as essential norms and basics of the health care system itself.

First, it is necessary to have a strong government leadership in public health policy and to promote health as a basic right, both nationally and internationally. Such leadership should be in accordance with the establishment of a firm governmental policy agenda, independent from external elements such as and including international organizations and other countries.

Second, health care should be focused on preventive and primary care in such a way that costs and potential sufferings of patients be reduced to a minimum. Focus on horizontal care will be a cost-effective long-term concern with the aim of improving the population's well-being. Third, health care should be community-oriented: it is effective in building trust, which in turn, will be helpful in determining health priorities and actions. Such participation can provide behavior modification services in areas such as and including smoking, weight, exercise, and substance dependence (Amadeo 2019, 19).

Fourth, the government should focus on training a substantial medical workforce including health workers, physicians and nurses in order to provide free medical education (Amadeo 2019, 20). Fifth, it is crucial to address nonmedical determinants of health in social, cultural and psychological settings. For this, such contexts of education, nutrition, employment, housing and sanitation should be considered (Spiegel and Yassi 2004, 94.; De Vos and Stuyft 2009, 1576). By addressing health disparities, the government can empower people and create a healthy community environment.

Sixth, the government should carry out equity-based health policies, paying attention to the most vulnerable groups and giving priority to women, children and elders. Seventh, annual check-up and screening procedure should be carried out: this entails categorization, close care and early diagnosis. Eighth, effective epidemic prevention strategies are necessary, for instance, a fumigation and hygiene campaign. Ninth, a strong family doctor system is recommended. The system should be integrated, collaborative, measurable, and multi-institutional. There should be a shared responsibility for community health in promotion, prevention, accessibility, and delivery (Keck, and Reed 2012, 19).

To complement the weakness of Cuba's health care system, the following recommendations are provided: first, it is necessary to have methods of reflecting consumer satisfaction and opinion on health care policies. To be 
competitive in the field of advanced medical care, there should be government spending in research and development in biotechnology. Computerization of health data for effective health care is also suggested (Spiegel and Yassi 2004, 98). It is also possible to leave a manageable margin for competition between public and private health care services in order to decrease the cost of medicine.

This section will have a brief comparison with North Korea's health care system. Despite similarity in economic isolation and socialist nature of the government, Cuba and North Korea have shown great disparity in their health outcomes. While Cuba's population has been benefitted from preventive care, along with mothers receiving adequate care and attention from family doctors next to their houses, North Korea's health care left with malnourished babies with its health care without sufficient improvement. The reasons have to do with government preparation and policy planning. Cuba has taken a systemic reform in face of economic isolation, with recognizing right-based approach, inculcating socialist ideals and ethics on people. Cuba has found best possible means to continue its health care and tried its best effort to initiate, continue and sustain its health care system. This can be seen from its continuous boosting of health workers with pride, and expansion of health education and further, internationalizing of their distinctive health care power to neighbour states. North Korea, by contrast, only focused its effort in military spending and nuclear weapon. The attention of the government was on increasing military capacity and finding lucks in gambling with other powers in exchange of nullifying its realist ambitions only to short term. Rather than long-term strategies to withstand government shocks in face of global reaction to nuclear experiments and leaving some redundancies in food supplies and policy mechanisms, for example, North Korean government focused on playing dangerous give and take game with Western powers barely affected by North Korea's nuclear weapons in truth. The World Food Program offers approximately half of one pregnant women's food in Songrim, North Korea. Upon visiting the hospital, the pregnant women only had $5 \mathrm{~kg}$ of cereals at home without protein consumption. The women mentioned that $70 \%$ of income earned by entire family, about US $\$ 3-5$ monthly is for food. She was frank in saying "without the donations, we couldn't manage" (Watts 2003, 2073). Such drastic contrast in focus, planning of government policies had induced such great disparity: Cuba's intact preventive care system while North Korea's health care system only got worsened. 


\section{CONCLUSION}

The research questions are: what lessons can be learned from the Cuban health care system, and is its success attributed to its unique economic and social situation or can this be transferrable to other countries? Considering categorization of emerging key themes into six different criteria for health care system, assessing their policy implications, reviewing responses and outcomes, and lastly laying out policy recommendations, this paper concludes that Cuba's socialist ideology and its desire to gain legitimacy for the rule made Cuba place focus on the general health of the population. With its limited resources, Cuba has been able to manage its health care system with a large number of family doctors. On the intrusive level, the Cuban government has used them as representatives of the regime that performs surveillance on the people. A healthy population from preventive care would, in turn, contribute to the economic growth of the country, which is currently situated in isolation. Other countries can learn from Cuba's preventive care and apply it in their own context. Thus, the system might be transferrable to other countries if there exists a capacity for primary and holistic care while at the same time improving upon the intrusive nature of the health care system in Cuba. Regarding feasibility, a public health care system should be prioritized over a private one. Cuba's awareness of health as the basic human right should be learned from. Also, Cuba's unavoidable choice to place emphasis on preventive care, despite some pitfalls being intrusive, should take into account to conditions of other countries, given successful results.

Furthermore, this paper recalls a form of biopolitics which was exercised by Cuban government over its population. Despite Foucault's application of governmentality in neoliberal democracy, this paper advances his theory by applying governmentality to non-western and socialist government regime. Despite shortage of autonomy of population reflecting back to biopolitical control imposed by the state government, the concept is alive as it encompasses systemic, and analysable Cuban health care system with mix of centralization and decentralization. The accumulation of population's data for health purpose also reflects biopolitics where the government plays a surveillance actor like as a centralized entity in a panopticon system.

Lastly, this review concludes with the prospect of Cuba's health care system while the US has recently lifted its embargo on Cuba. Cuba is therefore no longer in economic isolation and will be able to solve the issue of scarce medical supplies. Furthermore, people should recognize Cuba's increasing geopolitical influence in the world through free and low medical services. 70 countries were 
given paid or free medical service by Cuba's 35000 workers; it is estimated to be 70 million people (Keck, and Gail 2012, 18). These efforts should be lessons for those countries that are easily swayed by financial self-interests.

\section{REFERENCES}

Amadeo, Kimberly. 2009. "What Is Obamacare? The ACA and What You Need to Know." The Balance (June 25).

Brotherton, P. Sean. 2012. Revolutionary medicine: health and the body in post-Soviet Cuba. Duke University Press.

Cooper, Richard S., Joan F. Kennelly, and Pedro Ordunez-Garcia. 2006. "Health in Cuba." International Journal of Epidemiology 35 (4), 817824.

De Vos, Pol. 2005. “"No one left abandoned”: Cuba's national health system since the 1959 revolution." International Journal of Health Services 35(1), 189-207.

De Vos, Pol, and Patrick Van der Stuyft. 2009. "The right to health in times of economic crisis: Cuba's way." The Lancet 374 (9701), 1575-1576.

Drain, Paul K., and Michele Barry. 2010. "Fifty Years of US Embargo: Cuba's health Outcomes and lessons." Science 328 (5978), 572-573.

Essif, Mason. 2002. "Mason Essif Cuba Report." The Henry J. Kaiser Family Foundation (Dec 12). Accessed at https://www.kff.org/other/masonessif-cuba-report/ (Nov 8, 2016).

Feinsilver, Julie. 2016. "Cuba's Health Politics: At Home and Abroad." Council on Hemispheric Affairs. (29 Aug). Accessed at http://www.coha.org/ cuba\%E2\%80\%99s-health-politics-at-home-and-abroad 2016. (Nov 20 2016).

Frist, Bill. 2010. "A look inside Cuba's family clinics." Forbes (February 27).

Grandin, Greg. 2016. "Zika is circling Cuba. What will happen when it lands?" The Nation (Feb 2)

Herrera-Valdes, Raul, and Miguel Almaguer-Lopez. 2005. "Strategies for national health care systems and centers in the emerging world: Central America and the Caribbean-The case of Cuba." Kidney International 68, S66-S68.

Herzog, Richard J., Katie Counts McClain, and Kymberleigh R. Rigard. 2016. "Governmentality, biopolitical control, and a value pluralist perspective of wellness programs: creating utopian employees." Administrative Theory \& Praxis 38(1), 37-51. 
Hill, Fiona. 2015. "Prevention better than cure in Cuban healthcare system." $B B C$ (Dec 13)

Keck, C. William, and Gail A. Reed. 2012. "The curious case of Cuba." American journal of public health 102(8), e13-e22.

Kotkas, Toomas. 2010. "Governing health and social security in the twentyfirst century: active citizenship through the right to participate." Law and Critique 21(2), 163-182.

Magnussen, Lesley, John Ehiri, and Pauline Jolly. 2004. "Comprehensive versus selective primary health care: lessons for global health policy." Health affairs 23 (3), 167-176.

Nordlinger, Jay. 2007. "The Myth of Cuban Health Care." National Review (July 11).

Pagliccia, Nino, and Adolfo Álvarez Pérez. 2012. "The Cuban experience in public health: does political will have a role?." International Journal of Health Services 42(1), 77-94.

Spiegel, Jerry M., and Annalee Yassi. 2004. "Lessons from the margins of globalization: appreciating the Cuban health paradox." Journal of public health policy 25(1), 85-110.

Starfield, Barbara, Leiyu Shi, and James Macinko. 2005. "Contribution of primary care to health systems and health." Milbank quarterly 83(3), 457-502.

Thomas, Joel G. 2016. "Historical reflections on the post-soviet Cuban healthcare system, 1992-2009.” Cuban Studies 44(1),189-213.

Watts, Jonathan. 2003. "Health-care divide widens in North Korea." The Lancet 362(9401), 2072-2072.

WHO. 2008. "Cuba's primary health care revolution: 30 years on." WHO (May 5) Accessed at https://www.who.int/bulletin/ volumes/86/5/08-030508/en/ (Nov 8, 2016).

[Received May 15, 2019; Revised Jun 18, 2019; Accepted Jul 24, 2019] 